\title{
Circle Health is not like the John Lewis Partnership
}

\author{
Martin McKee professor of European public health \\ London School of Hygiene and Tropical Medicine, London WC1H 9SH, UK
}

It is nonsense to describe Circle Health as a "John Lewis style social enterprise." As the Observer has described in some detail, it is a loss making private business with financial arrangements that are far more complex than this article portrays. Staff shares amount to only $49 \%$ of the total number of shares, and the staff's decision making powers are far less than even this suggests. ${ }^{2}$ It would have been more helpful if, instead of trotting out the official line on this bizarre exercise, we could have had a serious discussion about how Circle Health can possibly make any money from this venture-given that this has baffled many independent commentators - and why so many hedge fund managers have rushed to invest in it. Is it simply a loss leader for richer pickings elsewhere? Something doesn't add up.

Competing interests: None declared.

1 Hawkes N. NHS hospital is taken over by a private social enterprise. BMJ 2011;343:d7341 (11 November.)

2 Circle Health-the "social enterprise" run by the world's hardest hedge fund managers. Observer 2011. www.guardian.co.uk/business/2011/nov/13/circle-health-social-enterprisehedge-fund-manager?INTCMP=SRCH.

Cite this as: BMJ 2011;343:d7897

๑ BMJ Publishing Group Ltd 2011 